www.jmscr.igmpublication.org Impact Factor 5.244

Index Copernicus Value: 83.27 ISSN (e)-2347-176x ISSN (p) 2455-0450 crossref DOI: _https://dx.doi.org/10.18535/jmscr/v4i11.27

\title{
A Rare Cause of Sciatic Pain: Multiple Schwannoma of Sciatic Nerve
}

\author{
Authors \\ Kushal Agrawal, Sachin S Balwantkar, Vandana S Dube \\ B J Medical College and Sassoon Hospital, Near Railway Station, Pune-01, Maharashtra, India \\ Corresponding Author \\ Kushal Agrawal \\ Room No- 315 Lateral Building, Sassoon Hospital, Pune, Maharashtra \\ Email: kushal.101090@gmail.com, 7875177442
}

\begin{abstract}
We report a case of 35 year old male with complaints of swelling in posterior aspect of left thigh since 9 years and pain in left lower limb since 2 months. MRI showed two well defined discrete lesions in relation to left sciatic nerve suggestive of neurogenic tumor. Postoperatively patient recovered well with no pain or neurological deficit.
\end{abstract}

Keywords- left sciatic nerve, neurogenic tumor.

\section{INTRODUCTION}

Sciatica is caused by irritation or compression of one of the 5 spinal nerve roots or nerve trunks and is usually is characterised by pain along the back, buttock, thigh, leg, and foot. Only $1 \%$ of sciatica is caused by schwannoma of sciatic nerve. Its symptoms of nerve root deficit is often confused with that caused by lumbar disc herniation. (1-3) Schwannoma of sciatic nerve are very rare $(1 \%)$ and diagnosis are often delayed for a long period of time. We report a very rare case of schwannomatosis along the left sciatic nerve with no associated neurofibromatosis.

\section{CASE REPORT}

A 35 year old male came with complaints of swelling in posterior aspect of left thigh since 9 years and pain in left lower limb since 2 months. Patient developed a swelling 9 years back in posterior aspect of left thigh which was insidious in onset gradually progressive. Also patient developed a similar swelling shortly after the first swelling just above the popliteal fossa of left lower limb. It was non tender. There was no pain associated initially but patient developed pain for 2 months for which he presented in the hospital. Pain was dull aching, continuous and more in morning hours just after waking up.

Mri was suggestive of two well defined discrete lesions noted in intermuscular plane of popliteal fossa and posterior compartment of left lower thigh. These lesions measures $5.2 * 5.2 * 7.8 \mathrm{~cm}$ and $4.6 * 5.3 * 8.9 \mathrm{~cm}$ in size. These lesion appear isointense on $\mathrm{T} 1 \mathrm{~W}$ images, heterogeneously hyperintense on T2W/PDFS/STIR images. These lesions show mild enhancement on post contrast images. No e/o blooming seen on GRE images within these lesions. These lesions are seen along 


\section{JMSCR Vol||04||Issue||11||Page 13683-13685||November}

course of sciatic nerve. f/s/o neurogenic tumor mostly schwannoma involving left sciaticnerve.

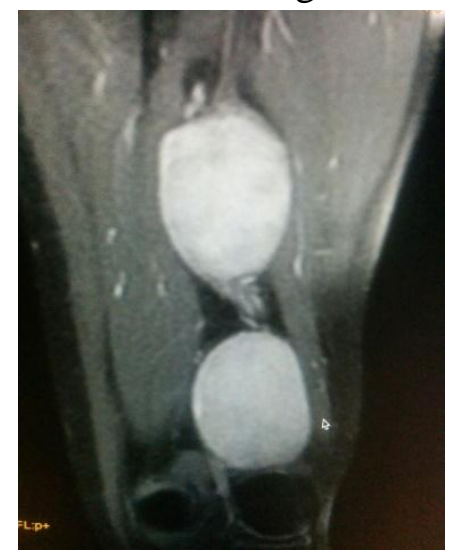

A preoperative biopsy showed spindle shaped cells and verrocay bodies and was suggestive of schwannoma.

Patient was operated. Two tumor of sciatic nerve were observed and removed. Postoperatively patient recovered completely with no neurological deficit of left lower limb pain. Patient was discharged on $5^{\text {th }}$ postoperative day.

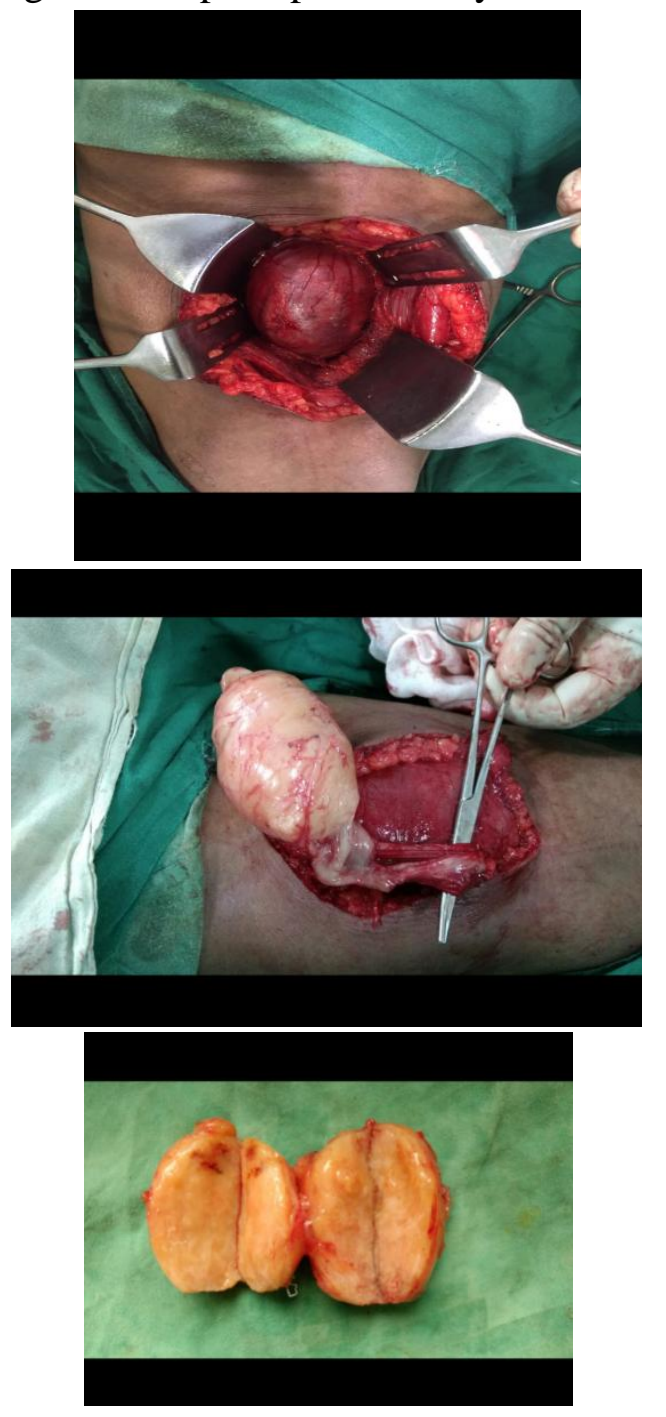

Histopathological specimen showed hypercellular Antony A area and hypocellular Antony B areas, showed spindle shaped cells with oval to spindle nuclei showing nuclear palisading with nuclei free zone (verrocay bodies) and was suggestive of schwannoma.

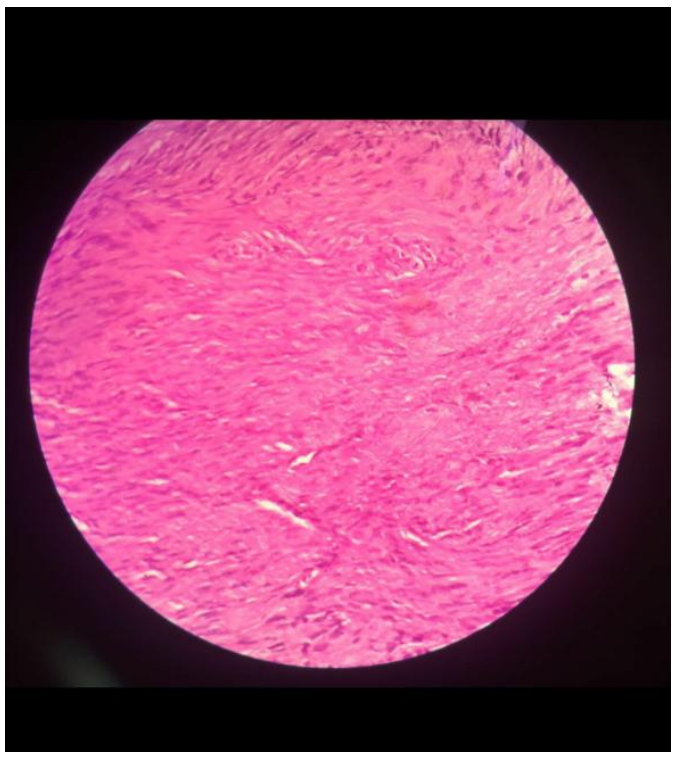

\section{DISCUSSION}

Peripheral nerve tumors are rare. They arise from the nerve sheath, which is derived from the neuroectoderm and neural crest cells. Schwannomas are the most common peripheral nerve sheath tumor. ${ }^{(4)}$ Most frequently involved nerve of lower limb is the posterior tibial nerve, usually at the tarsal sinus. ${ }^{(1)}$. Sciatic nerve involvement is rare and is around 1 in 100 cases. The incidence of sciatic schwannoma is 0.6 in 100000 people. ${ }^{(3)}$

Schawannomas mostly affects adults of the age of 20-50 years with no distinction of gender. Occurrence of multiple schwannomas is rare and is not always related to neuro fibromatosis ${ }^{(5)}$, as in this case. Schwannomas have a long subclinical course and their clinical presentation is misleading. MRI imaging of the limb confirms the diagnosis of peripheral nerve sheath tumor.

The main differential diagnosis of schwannoma is neurofibroma. Schwannomas originate from proximal nerve or spinal nerve roots and are usually solitary, well circumscribed, encapsulated and eccentrically located on nerve roots. Whereas, neurofibroma arise from distal nerves causing fusiform enlargement. Also, they are multiple and 
lack tumor capsule. ${ }^{(2)}$. Other rare differentials include inta-nervous lipoma, hemangioma of schwann sheath and neurolipofibroma. Malignant transformation of schwannoma is rare. It is almost $5 \% .{ }^{(6)}$

Surgical excision is the treatment of choice. Since schwannoma arise within the nerve sheath and are surrounded by true capsule comprising of epineurium, they can be completely enucleated and excised en mass without damage to the nerve. (7). Schwannomas have a good prognosis and a low incidence of recurrence and malignant transformation as compared to neurofibromatosis. Sciatic nerve fascicles are sometimes incorporated peripherally on tumor capsule thus requiring to be sacrificed. ${ }^{(9)}$ Therefore expertise in peripheral nerve surgery is necessary to reduce the risk of neurological deficit. ${ }^{(8)}$

Therefore, though rare, sciatic nerve schwannoma should be considered a cause of sciatica in young adults. MRI helps in the diagnosis and ruling out the differentials. Although, confirmation is done after histopathological examination.

\section{DISCLOSURE}

No conflicts of interest were declared by the authors.

\section{REFERENCES}

1. Kralick F., Koenigsberg R. Sciatica in a patient with unusual peripheral nerve sheath tumors. Surg Neurol. 2006;66:634637. [PubMed]

2. Rekha A., Ravi A. Sciatic nerve schwannoma. Int J Low Extrem Wounds. 2004;3:165-167. [PubMed]

3. Nawabi D.H., Sinisi M. Schwannoma of the posterior tibial nerve: the problem of delay in diagnosis. J Bone JtSurg Br. 2007;89:814-816. [PubMed]

4. Martinez Algarra J.C., Gastaldi Rodrigo P., PalomaresTalens E. Le schwannome multiple du nerfsciatique. À propos d'un cas. Rev ChirOrthopReparatriceAppar Mot. 1999;85:632-635. [PubMed]
5. Topsakal C., Akdemir I., Tiftikci M., Ozercan I., Aydin Y. Malignant schwannoma of the sciatic nerve originating in a spinal plexiformneurofibroma associated with neurofibromatosis type 1 - case report. Neurol Med Chir (Tokyo) 2001;41:551-555. [PubMed]

6. Rezzouk J., Durandeau A. Compression nerveuse par pseudokystemucoïde: à propos de 23 cas. Rev Chir Orthop Reparatrice Appar Mot. 2004;90:143-146. [PubMed]

7. Calisaneller $\mathrm{T}$, Gok $\mathrm{H}$, Yilmaz MS, Cinar GK, Naderi S. Schwannoma of sciatic nerve: a rare cause of nondiscogenic sciatica. World Spinal Column J 2011;2:77-80.

8. Oberle J, Kahamba J, Richter HP. Peripheral nerveschwannomas--an analysis of 16 patients. ActaNeurochir (Wien) 1997;139:949-53.

9. Créteur V., Bacq C., Fumière E., Bissen L., Delcour C. Échographie des nerfspériphériques. Deuxièmepartie: membreinférieur. J Radiol. 2007;88:349360. [PubMed] 